\title{
Incidence of insulin-requiring diabetes in the US military
}

\author{
E. D. Gorham • E. Barrett-Connor • \\ R. M. Highfill-McRoy • S. B. Mohr • C. F. Garland • \\ F. C. Garland • C. Ricordi
}

Received: 11 June 2009 / Accepted: 19 June 2009 /Published online: 24 July 2009

(C) The Author(s) 2009. This article is published with open access at Springerlink.com

\begin{abstract}
Aims/hypothesis The aim of the study was to determine age- and race-related, and overall incidence rates of insulinrequiring diabetes in adults in the US military.

Methods Electronic records for admissions to US military and Tricare hospitals during 1990-2005 and visits to military clinics during 2000-2005 were identified using the Career History Archival Medical and Personnel System at the Naval Health Research Center, San Diego, CA, USA. Population data were obtained from the Defense Manpower Data Center and Defense Medical Epidemiology Database. Results In men there were 2,918 new cases of insulinrequiring diabetes in 20,427,038 person-years at ages 18 44 years (median age 28 years) for a total age-adjusted incidence rate of 17.5 per 100,000 person-years $(95 \%$ CI 16.4-18.6). Incidence rates were twice as high in black men as in white men (31.5 vs 14.5 per $100,000, p<0.001)$. In
\end{abstract}

Electronic supplementary material The online version of this article (doi:10.1007/s00125-009-1449-x) contains supplementary material which is available to authorised users.

E. D. Gorham • R. M. Highfill-McRoy • S. B. Mohr •

F. C. Garland

Naval Health Research Center,

San Diego, CA, USA

E. D. Gorham $(\triangle) \cdot$ E. Barrett-Connor $\cdot$ S. B. Mohr •

C. F. Garland · F. C. Garland

Department of Family and Preventive Medicine,

University of California, San Diego,

140 Sylvester Road,

San Diego, CA 92106-3521, USA

e-mail: edward.gorham@med.navy.mil

C. Ricordi

Diabetes Research Institute, University of Miami,

Miller School of Medicine,

Miami, FL, USA women there were 414 new cases in 3,285,000 personyears at ages 18-44 years (median age 27 years), for a total age-adjusted incidence rate of 13.6 per 100,000 (95\% CI 12.4-14.9). Incidence rates were twice as high in black women as in white women (21.8 vs 9.7 per 100,000, $p<0.001)$. In a regression model, incidence of insulinrequiring diabetes peaked annually in the winter-spring season (OR 1.46, $p<0.01)$. Race and seasonal differences persisted in the multivariate analysis.

Conclusions/interpretation Differences in incidence rates by race and season suggest a need for further research into possible reasons, including the possibility of a contribution from vitamin $\mathrm{D}$ deficiency. Cohort studies using prediagnostic serum 25-hydroxyvitamin D should be conducted to further evaluate this relationship.

Keywords Incidence rates · Insulin-requiring diabetes · Race $\cdot$ Seasonality $\cdot$ Sex $\cdot$ Vitamin D $\cdot$ Young adults

\author{
Abbreviations \\ CHAMPS Career History Archival Medical and \\ Personnel System \\ DMED Defense Medical Epidemiology Database
}

\section{Introduction}

Insulin-requiring diabetes is the second most common chronic disease of childhood in the USA after asthma [1]. There are thought to be $15,000-30,000$ new cases of insulin-requiring diabetes in childhood in the USA annually. However, there are few reports on population-based incidence data for the disease [1-4]. This limits the validity of current estimates of the burden of disease. The present study reports the age- 
specific incidence of insulin-requiring diabetes in adult men and women, and its association with race and season.

\section{Methods}

Persons with insulin-requiring diabetes are not allowed to join the US military. As a result, first hospitalisations or clinic visits during military service represent incident cases. Hospitalisation data from military hospitals were obtained from the Tricare Executive Information and Decision Support System, Standard Inpatient Data Record (SIDR), which includes discharge summaries of all admissions. Hospitalisation data from civilian Tricare hospitals were obtained from the Tricare Health Care Service Record (HCSR) database. Outpatient records of treatment in military clinics were obtained from the Standard Ambulatory Data Record (SADR) database, which included outpatient visits to all military clinics worldwide in 2000 2005. Tricare hospitals and military outpatient clinics have participated in the current records system since 2000.

Electronic records of inpatient encounters were identified for service members aged 18-44 years who were hospitalised with a discharge diagnosis of insulin-requiring diabetes in any military hospital during 1990-2005, in a civilian Tricare hospital during 2000-2005, or treated in any outpatient military clinic worldwide during 2000-2005.

Data on hospitalisations and clinic visits were entered on a monthly basis into the Career History Archival Medical and Personnel System (CHAMPS) maintained by the Naval Health Research Center (San Diego, CA, USA). A CHAMPS history consists of an individual record for each service member. It includes medical and career events and captures admissions to any military or Tricare hospital, or visits to any military outpatient clinic in the world.

Case definition A case was defined as: (1) any individual who had a hospital discharge diagnosis of insulin-requiring diabetes (ICD9-CM Codes 250.X1 or 250.X3, where X is 0-9; www.icd9data.com/2007/Volume1) in either a US Department of Defense medical treatment facility or a Tricare civilian hospital; (2) any individual who had at least three outpatient visits listing type 1 diabetes as the diagnosis during any 12 month period; or (3) any individual who had at least seven outpatient visits with a diagnosis of insulin-requiring diabetes during their military career. The reason for requiring multiple clinic visits for identification as a case is that insulinrequiring diabetes was occasionally recorded as a tentative diagnosis explaining a clinic visit pending confirmation by laboratory data. A review of records revealed that when there were three or more clinic visits for insulin-requiring diabetes in a 12 month period, the individual generally had more than ten subsequent visits for evaluation and treatment of insulin- requiring diabetes or received a discharge from service due to diabetes.

Denominator data were obtained from the Defense Medical Epidemiology Database (DMED; Silver Spring, MD, USA) of the US Army and the Defense Manpower Data Center-West (Seaside, CA, USA). All records were maintained in CHAMPS, which is a federally designated system of records, with strict precautions regarding maintenance of confidentiality of patient health information.

Incidence rates in the Department of Defense population were adjusted to the US standard population in 2000 [5] using the direct method [6]. The 95\% CI were calculated using the Poisson distribution [6]. Multiple logistic regression was used to adjust for age, sex, race and season. The criterion for statistical significance of all analyses in the study was an alpha level of 0.05 , two-tailed.

Multiple regression analysis was performed using all cases during 2000-2004 and a probability sample of noncases who were on active duty in the military at the time of first diagnosis of the cases. All analyses were performed using SAS-PC, version 7.0 PROC FREQ and PROC LOGISTIC (SAS Institute, Cary, NC, USA).

\section{Results}

In men, there were 2,918 newly diagnosed cases of insulinrequiring diabetes at ages 18-44 years (median age 28 years) in 20,427,038 person-years at risk (Table 1). The overall age-standardised incidence rate in men was 17.5 per 100,000 person-years. Incidence rates in black men were approximately double those in white men $(p<$ 0.001 ), and rose consistently with age (Table 1 ).

In women, there were 414 newly diagnosed cases of insulin-requiring diabetes at ages 18-44 years (median age 27 years) in 3,285,000 person-years at risk (Table 1), corresponding to an age-standardised incidence rate of 13.6 per 100,000 person-years. Incidence rates in black women were approximately double those in white women $(p<$ 0.001 , Table 1). Incidence rates in men and women of other ethnicities were generally intermediate between those of white and black people (Table 1). The higher rates in black persons and in late winter (see Electronic Supplementary Material [ESM] Fig. 1) persisted after adjustment for age and sex, indicating that being black and winter season were independently associated with risk of insulin-requiring diabetes (Table 2).

\section{Discussion}

This study found substantially higher incidence rates of insulin-requiring diabetes in blacks and marked seasonal 
Table 1 Annual age-specific and age-adjusted incidence rates of insulin-requiring diabetes per 100,000 person-years by race and sex (active duty service members) (Department of Defense, 1990-2005)

\begin{tabular}{|c|c|c|c|c|c|c|c|c|c|}
\hline \multirow[t]{2}{*}{ Age (years) } & \multicolumn{3}{|l|}{ White } & \multicolumn{3}{|l|}{ Black } & \multicolumn{3}{|l|}{ Other } \\
\hline & $\begin{array}{l}\text { No. of } \\
\text { new cases }\end{array}$ & $\begin{array}{l}\text { No. of } \\
\text { person-years } \\
\text { at risk }\end{array}$ & $\begin{array}{l}\text { Annual rate } \\
\text { per100,000 } \\
\text { person-years }\end{array}$ & $\begin{array}{l}\text { No. of } \\
\text { new cases }\end{array}$ & $\begin{array}{l}\text { No. of } \\
\text { person-years } \\
\text { at risk }\end{array}$ & $\begin{array}{l}\text { Annual rate } \\
\text { per } 100,000 \\
\text { person-years }\end{array}$ & $\begin{array}{l}\text { No. of } \\
\text { new cases }\end{array}$ & $\begin{array}{l}\text { No. of } \\
\text { person-years } \\
\text { at risk }\end{array}$ & $\begin{array}{l}\text { Annual rate } \\
\text { per } 100,000 \\
\text { person-years }\end{array}$ \\
\hline \multicolumn{10}{|l|}{ Men } \\
\hline$<20$ & 122 & $1,203,505$ & 10.1 & 26 & 269,053 & 9.7 & 3 & 130,811 & 2.3 \\
\hline $20-24$ & 537 & $4,979,268$ & 10.8 & 173 & $1,166,034$ & 14.8 & 32 & 544,029 & 5.9 \\
\hline $25-29$ & 363 & $3,212,950$ & 11.3 & 152 & 860,290 & 17.7 & 21 & 356,393 & 5.9 \\
\hline $30-34$ & 321 & $2,465,765$ & 13.0 & 197 & 707,407 & 27.8 & 23 & 263,237 & 8.7 \\
\hline $35-39$ & 334 & $2,058,562$ & 16.2 & 241 & 584,540 & 41.2 & 31 & 216,669 & 14.3 \\
\hline $40-44$ & 195 & $1,045,387$ & 18.7 & 128 & 241,992 & 52.9 & 19 & 121,146 & 15.7 \\
\hline Total & 1,872 & $14,965,437$ & 12.5 & 917 & $3,829,316$ & 23.9 & 129 & $1,632,285$ & 7.9 \\
\hline Age-adjusted rate & & & 14.5 & & & 31.5 & & & 13.5 \\
\hline $95 \% \mathrm{CI}$ & & & $13.6-15.4$ & & & $29.6-33.5$ & & & $11.6-15.7$ \\
\hline \multicolumn{10}{|l|}{ Women } \\
\hline$<20$ & 11 & 193,854 & 5.7 & 20 & 89,624 & 22.3 & 4 & 31,053 & 12.9 \\
\hline $20-24$ & 72 & 711,972 & 10.1 & 41 & 347,665 & 11.8 & 5 & 113,790 & 4.4 \\
\hline $25-29$ & 47 & 435,330 & 10.8 & 43 & 247,970 & 17.3 & 10 & 64,861 & 15.4 \\
\hline $30-34$ & 32 & 288,039 & 11.1 & 56 & 180,873 & 31.0 & 7 & 36,145 & 19.4 \\
\hline $35-39$ & 27 & 222,473 & 12.1 & 19 & 130,233 & 14.6 & 2 & 22,807 & 8.8 \\
\hline $40-44$ & 8 & 107,953 & 7.4 & 10 & 50,031 & 20.0 & 0 & 10,327 & 0.0 \\
\hline Total & 197 & $1,959,621$ & 10.1 & 189 & $1,046,396$ & 18.1 & 28 & 278,983 & 10.0 \\
\hline Age-adjusted rate & & & 9.7 & & & 21.8 & & & 11.1 \\
\hline $95 \% \mathrm{CI}$ & & & $8.4-11.2$ & & & $18.9-25.1$ & & & $7.4-16.0$ \\
\hline
\end{tabular}

The total annual age-adjusted incidence rate for the whole population was 17.5 (95\% CI 16.4-18.8) per 100,000 person-years in men and 13.6 (95\% CI 12.4-14.9) per 100,000 person-years in women. The $p$ values for the difference in incidence rates between white and black men was $<0.001$, and in women it was also $<0.001$. The median age of the cases was 28 years in men and 27 years in women

Table 2 Estimated relative risk of insulin-requiring diabetes according to age, sex, race, and quarter (Department of Defense service members, 2000-2004)

\begin{tabular}{|c|c|c|c|c|c|c|}
\hline Covariate & $R$ & $\mathrm{SE}$ & $t$ & OR & $95 \% \mathrm{CI}$ & $p$ value \\
\hline \multicolumn{7}{|l|}{ Age (years) } \\
\hline $18-24$ & & & & 1.00 & Reference & \\
\hline $25-34$ & 0.129 & 0.067 & 1.9 & 1.14 & $1.00-1.30$ & 0.05 \\
\hline$\geq 35$ & 1.657 & 0.072 & 23.0 & 5.25 & $4.56-6.04$ & $<0.001$ \\
\hline \multicolumn{7}{|l|}{ Sex } \\
\hline Male & & & & 1.00 & Reference & \\
\hline Female & -0.124 & 0.083 & -1.5 & 0.88 & $0.75-1.04$ & 0.14 \\
\hline \multicolumn{7}{|l|}{ Race } \\
\hline White & & & & 1.00 & Reference & \\
\hline Black & 0.748 & 0.060 & 12.5 & 2.11 & $1.88-2.38$ & $<0.01$ \\
\hline Other & 0.261 & 0.120 & 2.2 & 1.30 & $1.03-1.64$ & 0.03 \\
\hline \multicolumn{7}{|l|}{ Quarter } \\
\hline July-September & & & & 1.00 & Reference & \\
\hline October-December & 0.055 & 0.084 & 0.7 & 1.06 & $0.90-1.25$ & 0.52 \\
\hline January-March & 0.378 & 0.078 & 4.8 & 1.46 & $1.25-1.70$ & $<0.01$ \\
\hline April-June & 0.213 & 0.081 & 2.6 & 1.24 & $1.06-1.45$ & $<0.01$ \\
\hline
\end{tabular}


variation in incidence in all races combined, which peaked in late winter through early spring and were lowest in summer and early autumn (Table 2). There are few previous reports on racial differences in insulin-requiring diabetes incidence rates in young adults. A study of Navy-enlisted men during 1974-1988 found a higher incidence rate in blacks than whites (28.4 vs 20.2 per 100,000 person-years, respectively; $p<0.05$ ) [2]. Data presented here indicate that insulin-requiring diabetes occurs beyond childhood at a substantial incidence rate and that it appears to be more common in black than in white people at ages 18-44 years.

It is possible that some of the individuals in the population identified as cases of insulin-requiring diabetes may actually have type 2 diabetes. In addition, the observed age-related increase in incidence of insulin-requiring diabetes (Table 1) suggests that some cases of type 2 diabetes may have been included in the analysis because they were being given insulin. Therefore, caution should be exercised in drawing conclusions about whether insulin-requiring diabetes in this population is specifically type 1 or type 2 . On the other hand, most cases were hospitalised and the diagnosis of all was type 1 diabetes, indicating that all cases were receiving insulin at the time of hospital discharge.

Previous research has demonstrated an association between BMI and risk of insulin-dependent diabetes [7]. However, data on BMI were not available in the database used for the present study or any database available to the investigators for this population. Caution should be exercised when interpreting the results, as the higher risk observed in later age and in blacks may be due to higher BMI in these groups. Furthermore, the military population is not a probability sample of the US population, so the results cannot be generalised to the US population without caution.

Aetiology Several theories have been put forward in an effort to explain the epidemiology and cause of insulinrequiring diabetes, yet the identification of a causal factor has been elusive. The armed services actively promotes exercise, physical fitness and weight control, and as a result, might be expected to have a lower than average incidence rate of type 2 diabetes. However, there is less evidence that physical activity or weight influences the incidence of type 1 diabetes requiring insulin in children [8], unlike diabetes not requiring insulin. Differences in body mass between white and black populations have been proposed as possibly accounting for the higher incidence rate of type 2 diabetes in black people [9]; however, this explanation is not wholly applicable to young insulinrequiring diabetes patients, who are usually not overweight [8]. Some evidence suggests that blacks diagnosed with insulin-requiring diabetes are less likely than whites to have antibodies against islet-cell antigens, and that they may be more likely than whites to have type 2 diabetes presenting acutely as insulin-requiring diabetes [10].

Winter season and black skin pigmentation substantially reduce the photosynthesis of vitamin $\mathrm{D}_{3}$ in the skin, creating a high prevalence of vitamin $\mathrm{D}$ deficiency. The markedly higher incidence of insulin-requiring diabetes in black than in white people in the present study suggests the possibility that vitamin $\mathrm{D}$ deficiency might play some role in the differential incidence of insulin-requiring diabetes according to race, as suggested by previous research [11, 12]. If vitamin $D$ deficiency is a contributor to insulinrequiring diabetes $[11,12]$, it could help explain the seasonal and racial differences in incidence rates.

Acknowledgements This research was supported by a Congressional allocation to the Diabetes Research Institute, University of Miami, Miller School of Medicine in Miami, FL, USA, through the Department of the Navy, Bureau of Medicine and Surgery, under Work Unit No. 60126. The views expressed in this report are those of the authors and do not represent an official position of the Department of the Navy, Department of Defense or the US Government. The study has been approved for public release with unlimited distribution. The authors express their gratitude to: R. Guerin, Director, Tricare Health Programs Analysis and Evaluation Branch; S. Jenkins of the Tricare Management Activity Privacy Office; the Tricare Chief Information Officer and the staff of the Tricare Executive Information and Decision Support System. We also thank our Naval Health Research Center colleague E. E. K. Gunderson, who brought together the system of medical databases that were used to perform this study, M. Miller and T. Nedellec for maintaining the data sets that were used to perform the study, and S. Hilton for consultation on SPSS programming methods. Thanks are also extended to D. Washington of Tricare and Axion, who helped the authors obtain access to Tricare medical data, to M. Dove, V. Lauter and S. Seggerman of the Management Information and Analysis Division, Defense Manpower Data CenterWest, who provided data on population denominators, and to the Defense Medical Epidemiology Database of the Army, whose DMED online website provided denominator data for some analyses. We also thank A.A. Burgi (Naval Health Research Center), who read and commented on the manuscript.

Duality of interest The authors declare that there is no duality of interest associated with this manuscript.

Open Access This article is distributed under the terms of the Creative Commons Attribution Noncommercial License which permits any noncommercial use, distribution, and reproduction in any medium, provided the original author(s) and source are credited.

\section{References}

1. Melton LJ 3rd, Palumbo PJ, Chu CP (1983) Incidence of diabetes mellitus by clinical type. Diabetes Care 6:75-86

2. Gorham ED, Garland FC, Barrett-Connor E, Garland CF, Wingard DL, Pugh WM (1993) Incidence of insulin-dependent diabetes mellitus in young adults: experience of 1,587,630 U.S. Navy enlisted personnel. Am J Epidemiol 138:984-987 
3. LaPorte RE, Matsushima M, Chang YF (1995) Prevalence and incidence of insulin-dependent diabetes. In: Harris M, Cowie C, Stern M, Boyko E, Reiber G, Bennett P (eds) Diabetes in America, 2nd edn (National Institutes of Health Publication No 95-1468). National Institute of Diabetes and Digestive and Kidney Diseases, Bethesda, pp 37-46

4. LaPorte RE, Tajima N, Dorman J et al (1986) Differences between blacks and whites in the epidemiology of insulin-dependent diabetes in Allegheny County, Pennsylvania. Am J Epidemiol 123:592-603

5. National Cancer Institute (2007) Surveillance, Epidemiology, and End Results (SEER). Available from http://seer.cancer.gov, accessed 23 June 2009

6. Lilienfeld DE, Stolley PD (1996) Foundations of epidemiology, 3rd edn. Oxford University Press, Oxford

7. Fourlanos S, Harrison LC, Colman PG (2008) The accelerator hypothesis and increasing incidence of type 1 diabetes. Curr Opin Endocrinol Diabetes Obes 15:321-325
8. Mayer-Davis EJ, Bell RA, Dabelea D et al (2009) The many faces of diabetes in American youth: type 1 and type 2 diabetes in five race and ethnic populations: the SEARCH for Diabetes in Youth Study. Diabetes Care 32(Suppl 2):S99S101

9. Marshall MC Jr (2005) Diabetes in African Americans. Postgrad Med J 81:734-740

10. Leech NJ, Kitabchi AE, Gaur LK et al (1995) Genetic and immunological markers of insulin dependent diabetes in Black Americans. Autoimmunity 22:27-32

11. Hypponen E, Laara E, Jarvelin MR, Virtanen SM (2001) Intake of vitamin $\mathrm{D}$ and risk of type 1 diabetes: a birth cohort study. Lancet 358:1500-1503

12. Mohr SB, Garland CF, Gorham ED, Garland FC (2008) The association between ultraviolet $\mathrm{B}$ irradiance, vitamin $\mathrm{D}$ status and incidence rates of type 1 diabetes in 51 regions worldwide. Diabetologia 51:1391-1398 